\title{
Regularization of P-P and P-S converted waves data through the FO-CRS traveltime approximation
}

\author{
Raphael Di Carlo Silva dos Santos ${ }^{1}$, João Carlos Ribeiro Cruz², Alexandre Sodré Fernandes² \\ 1 Universidade Federal do Oeste do Pará \\ 2 Universidade Federal do Pará
}

\section{Copyright 2018, SBGf - Sociedade Brasileira de Geofísica}

Este texto foi preparado para a apresentação no VIII Simpósio Brasileiro de Geofísica, Salinópolis, 18 a 20 de setembro de 2018. Seu conteúdo foi revisado pelo Comite Técnico do VIII SimBGf, mas não necessariamente representa a opinião da SBGf ou de seus associados. É proibida a reprodução total ou parcial deste material para propósitos comerciais sem prévia autorização da SBGf.

\section{Abstract}

We present a new method of regularization of seismic data using the finite offset common reflection source (FOCRS) traveltime approximation. This method fits curves of common reflection source to the reflection events and stacks all the amplitudes in a given aperture. The stacked amplitude, afterwards, is allocated to the time coordinate in the trace to be interpolated. We applied this method to three synthetic velocity models and the results showed the capability for regularizing converted seismic waves in stratified medium.

\section{Introduction}

The seismic method is one of the most important geophysical methods for oil and gas exploration and reservoir monitoring. Through the seismic method is possible to image available structures which might be structural or stratigraphic traps. In order to process and to create a clear image which meets the interests of each exploration survey, it is necessary that the data acquisition does not experience any external conditions as irregular geophones spacing, high level of instrumental noise, short offsets or low coverage. In order for solving this problem, it is necessary the regularization of the seismic traces through interpolation.

Several methods of seismic data interpolation have been published using linear prediction (SPITZ, 1991), Fourier analysis (SACCHY;ULRICH, 1996; TRAD, 2009), Radon transform (TRAD et al, 2003; WANG; NG; PERZ, 2010) and the operator-oriented CRS (common reflection source) (HOECHT et al., 2009), however these methods experience irregularities of sparse data geometry requiring, then, additional efforts to solve the interpolation problem (XU et al., 2005).

We propose in this work to use the FO-CRS (finite offset common reflection source) in the CS (common shot) configuration - which uses attributes of the wavefield kinematics (JÄGER et al., 2001) of common shot sections - to interpolate seismic traces of P-P and P-S reflected waves.
We applied our methodology to noisy and noise-free synthetic seismic data by using horizontal and dip layers.

\section{FO-CRS traveltime}

According to Bortfeld (1989), Zhang et al. (2001) developed a hyperbolic traveltime approximation for paraxial rays in the vicinity of a central ray which considers a finite offset between source and receiver. Considering a central ray starting from $S$, reflecting at $R$ in the subsurface, and emerging at G (Fig.1), the traveltime of the finite offset paraxial ray is - also denoted as FOCRS traveltime - expressed by

$$
\begin{aligned}
& t^{2}\left(\Delta x_{m}, \Delta h\right)=\left[t_{0}+\left(\frac{\sin \beta_{G}}{v_{G}}+\frac{\sin \beta_{S}}{v_{S}}\right) \Delta x_{m}+\right. \\
& \left.\left(\frac{\sin \beta_{G}}{v_{G}}-\frac{\sin \beta_{S}}{v_{S}}\right) \Delta h\right]^{2}+t_{0}\left[\left(4 K_{1}-3 K_{3}\right) \frac{\cos ^{2} \beta_{G}}{v_{G}}-\right. \\
& \left.K_{2} \frac{\cos ^{2} \beta_{S}}{v_{S}}\right] \Delta x_{m}{ }^{2}+t_{0}\left[K_{3} \frac{\cos ^{2} \beta_{G}}{v_{G}}-K_{2} \frac{\cos ^{2} \beta_{S}}{v_{S}}\right] \Delta h+ \\
& 2 t_{0}\left[K_{3} \frac{\cos ^{2} \beta_{G}}{v_{G}}+K_{2} \frac{\cos ^{2} \beta_{S}}{v_{S}}\right] \Delta h \Delta x_{m},
\end{aligned}
$$

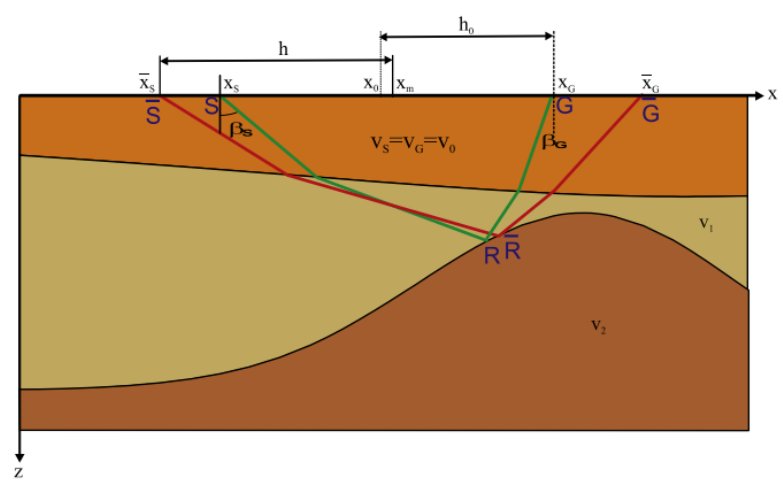

Figure 1 - Diagram of the paraxial ray at the vicinity of the central ray SGR in a layered and smooth model (modified from Garabito et al., 2011).

where $t_{0}$ is the traveltime along the central ray, $\beta_{\mathrm{s}}$ and $\beta_{\mathrm{G}}$ are the start and emergence angles, respectively, of the central ray at the position $S$ with coordinate $x S$ and at the position $\mathrm{G}$ with coordinate $x \mathrm{G}$. The displacements $\Delta \mathrm{x}_{\mathrm{m}}=$ $\mathrm{X}_{\mathrm{m}}-\mathrm{X}_{0}$ and $\Delta \mathrm{h}=\mathrm{h}-\mathrm{h}_{0}$ correspond to the midpoint and halfoffset, respectively, in which $x_{0}=(x G+x S) / 2$ is the midpoint and $h_{0}=(x G-x S) / 2$ is the half-offset of the central ray. The midpoint $x_{m}$ and the half-offset $h$ are the measured coordinates of a paraxial ray with finite offset. 
The velocity of the wave at the source and at the receiver are denoted by $\mathrm{v}_{\mathrm{S}}$ and $\mathrm{v}_{\mathrm{G}}$, respectively, and we admit $\mathrm{v}_{\mathrm{S}}=$ $\mathrm{V}_{\mathrm{G}}=\mathrm{V}_{0}$. The parameters $\mathrm{K}_{1}, \mathrm{~K}_{2}$ and $\mathrm{K}_{3}$ are the curvatures of the wavefront associated to the central ray computed in the earth surface.

The traveltime defined by eq. (1) aims to simulate CO (common offset) sections of multicoverage pre-stacked data. The Figure 2 illustrates the eq. (1): for each sample point $\mathrm{P}_{0}\left(\mathrm{x}_{0}, \mathrm{t}_{0}, \mathrm{~h}_{0}\right)$, in the $\mathrm{CO}$ section to be simulated, exists a stack surface defined by five parameters so that the seismic events fitted in this surface are summed and allocated in the coordinate of the point $\mathrm{P}_{0}$.

The eq. (1) shows the FO-CRS traveltime for a configuration of the coordinates source-receiver ( $x G, x S)$, however in this in this work we chose to use seismic sections for the case CS (commom shot). In this case in eq. (1), we insert the condition $\Delta x_{m}=\Delta h$, for which the sources of the paraxial and central ray coincide (GARABITO et al., 2011), providing the CS-CRS approximation by

$$
t^{2}(\Delta h)=\left[t_{0}+2 \frac{\sin \beta_{G}}{v_{G}} \Delta h\right]^{2}+4 t_{0}\left[K_{1} \frac{\cos ^{2} \beta_{G}}{v_{G}}\right] \Delta h^{2},
$$

also named as CS-CRS stacking curve.

(b)

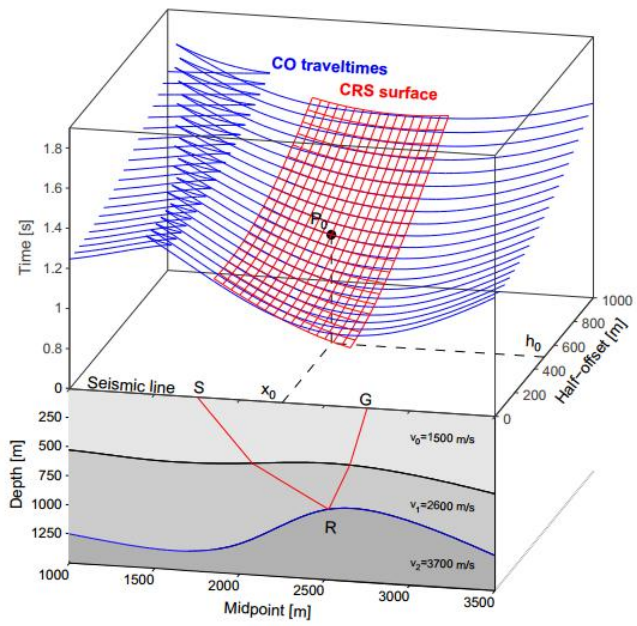

Figure 2 - (a) Smooth geophysical model with constant velocities in which the central ray $S G$ is reflected in the second layer. (b) $\mathrm{CO}$ traveltime curves associated with the CRS surface at the point $\mathrm{P}_{0}$. (modified from Garabito et al., 2011).

\section{Interpolation and stacking}

In numerical analysis, interpolation is the method of creation of new data through the set of previous known data. In a seismic section, the data need to be as regular as possible to avoid problems with posterior steps of processing and migration. Then when sections have no regular data due to operational problems in the survey, we need to regularize it.
In this paper, we propose an interpolation method by using eq. (2). For an effective fitting of the traveltime curve of the eq. (2), we have two ways, in the first (data driven) we consider a coherence measured which calculates quantitatively the similarity between multichanel data, e.g. the semblance function (NEIDELL \& TURNER, 1971), to generate an optimal fitting of the CS-CRS curve and to estimate the best CRS parameters. After we estimate the better semblance value, we stack all the amplitudes which fit the curve and we allocate the stacked amplitudes at the coordinate of the trace to be interpolated. For each seismic event we choose a value $t_{0}$ at the time coordinate in the trace to be interpolated and we fit it a CS-CRS curve. In the other way (model driven), we consider an a priori known velocity model (P-P or P$\mathrm{S}$ ), and by ray tracing we calculate the CRS parameters necessaries to fit the CS CRS curve to the seismic events, afterwards the stack process is similar to the anterior data driven case. In this work, we will apply the model driven alternative, for testing the performance of the regularization method by the CS CRS stacking curve.

\section{Synthetic Models}

We applied the interpolation in three velocity synthetic models. In all models we generated a CS seismic section using 30 geophones spaced $500 \mathrm{~m}$ each and the source coordinate is in the origin of the coordinate system. Also all the data were generated through the ray tracing method (CERVENY, 2001) and we deleted some traces to represent problems in the survey.

The first model, illustrated in the Figure $3 \mathrm{a}$, is made by one horizontal reflector splitting two layers. This model has $3 \mathrm{~km}$ in length and is $1 \mathrm{~km}$ deep. The coordinate of the reflector is $0.5 \mathrm{~km}$ in depth. The first layer has the $P$ wave velocity equal to $1.85 \mathrm{~km} / \mathrm{s}$ and $S$ wave velocity equal to $1.10 \mathrm{~km} / \mathrm{s}$. In the bottom, the layer holds the $P$ wave velocity equal to $2.4 \mathrm{~km} / \mathrm{s}$ and $\mathrm{S}$ wave velocity equal to $1.5 \mathrm{~km} / \mathrm{s}$ (Figure $3 \mathrm{~b}$ ).

The second model, illustrated in the figure $4 \mathrm{a}$, is made by two horizontal reflector splitting three layers. This model has $3 \mathrm{~km}$ in length and is $3 \mathrm{~km}$ deep. The coordinates of the reflectors are $1 \mathrm{~km}$ and $2 \mathrm{~km}$ in depth. The first layer holds the $P$ wave velocity equal to $2 \mathrm{~km} / \mathrm{s}$ and $S$ wave velocity equal to $1.15 \mathrm{~km} / \mathrm{s}$. The second layer holds the velocity of $P$ wave equal to $2.2 \mathrm{~km} / \mathrm{s}$ and the velocity of $S$ wave equals to $1.27 \mathrm{~km} / \mathrm{s}$. And the third layer holds the velocity of $P$ wave equal to $2.5 \mathrm{~km} / \mathrm{s}$ and the velocity of $S$ wave equals to $1.6 \mathrm{~km} / \mathrm{s}$ (figure $4 \mathrm{~b}$ ).

The third and last model, illustrated in the Figure $5 \mathrm{a}$, is made by one horizontal reflector and other one dip reflector splitting three layers. This model has $3 \mathrm{~km}$ in length and is $2 \mathrm{~km}$ deep. The coordinate of the horizontal reflector is $0.5 \mathrm{~km}$ in depth and the coordinate of the second reflector starts at $800 \mathrm{~m}$ and finishes at $600 \mathrm{~m}$ in depth. The first layer holds the velocity of $P$ wave equal to $2.3 \mathrm{~km} / \mathrm{s}$ and the velocity of $S$ wave equal to $2.09 \mathrm{~km} / \mathrm{s}$. The second layer holds the velocity of $P$ wave equal to $2.6 \mathrm{~km} / \mathrm{s}$ and the velocity of $S$ wave equal to $2.16 \mathrm{~km} / \mathrm{s}$. Finally the third layer holds the velocity of $P$ wave equal to $2.7 \mathrm{~km} / \mathrm{s}$ and the velocity of $\mathrm{S}$ wave equal to $2.25 \mathrm{~km} / \mathrm{s}$ (Figure 5b). 
(a)
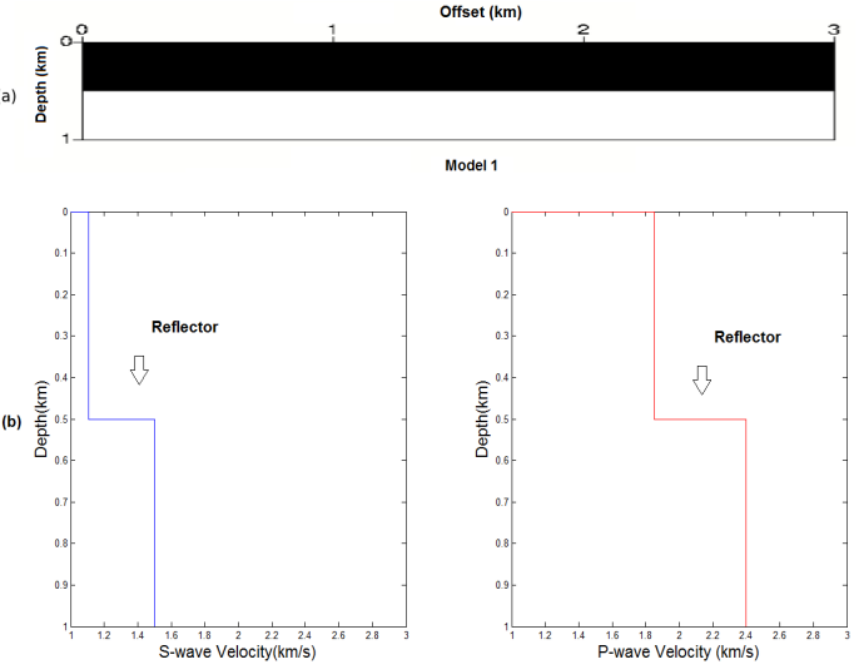

Figure 3 - (a) Synthetic velocity model 1. (b) S-wave velocity profile on the left and P-wave velocity profile on the right.
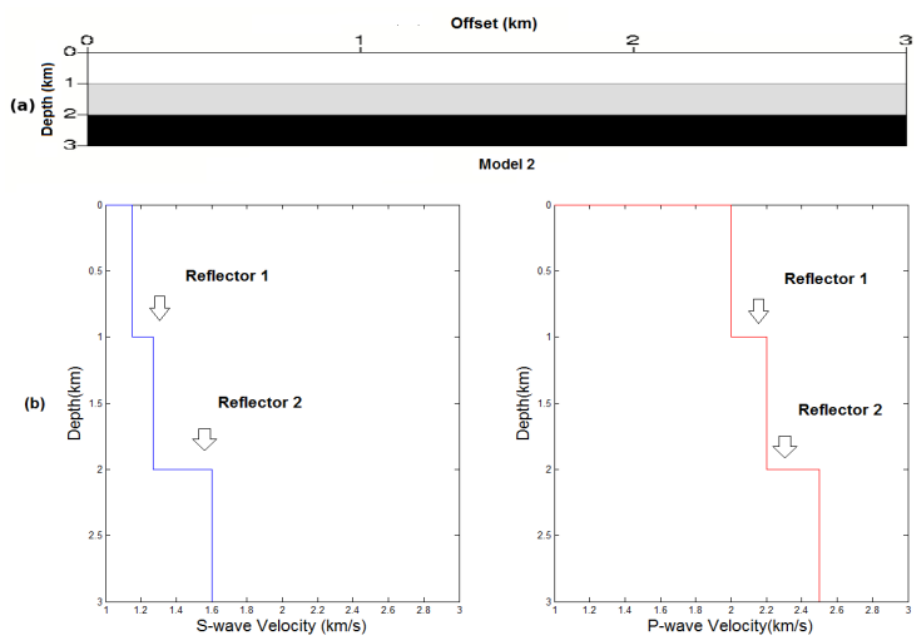

Model 2

Figure 4 - (a) Synthetic velocity model 2. (b) S-wave velocity profile on the left and P-wave velocity profile on the right.
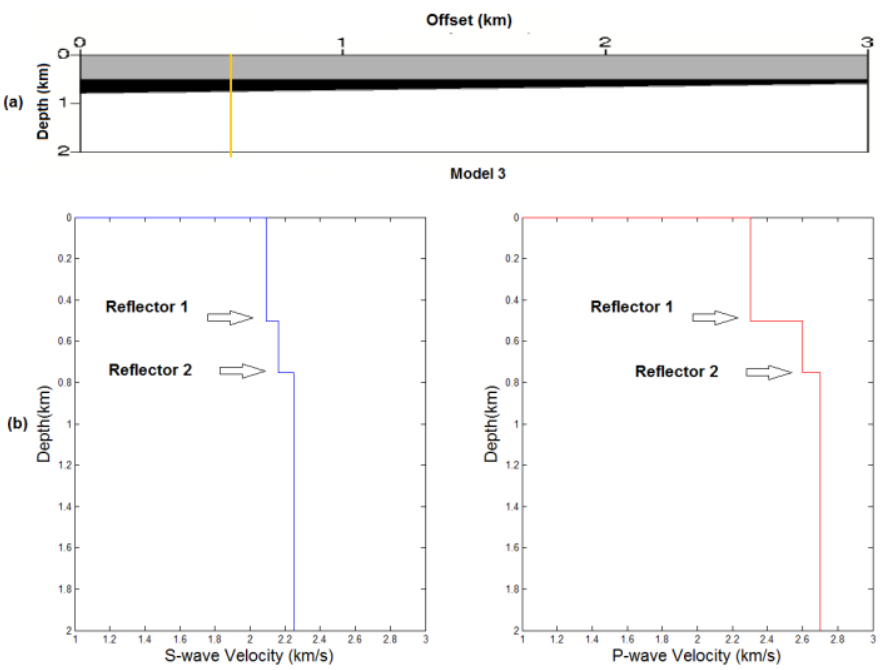

Figure 5 - (a) Synthetic velocity model 3 . Orange line indicates the coordinate of the velocity profile. (b) S-wave velocity profile on the left and P-wave velocity profile on the right.

\section{Results}

In the Figure 6 we have the CS-CRS curves corresponding the P-P and P-S reflections fitting the seismic section for the model 1. Moreover the trace 10 in the offset $1 \mathrm{Km}$ is deleted. The fitting parameters for the superior curve - which represents the P-P reflection - are $\mathrm{t}_{0}=0,974447 \mathrm{~s}, \quad \mathrm{~K}_{1}=0,55470019 \mathrm{~km}^{-1}$ and $\beta_{G}=$ $0,98279372 \mathrm{rad}$. For the inferior curve - which represents the P-S reflection - the fitting parameters are $t_{0}=1,2485 \mathrm{~s}$, $\mathrm{K}_{1}=0,98279372 \mathrm{~km}^{-1}$ e $\beta_{\mathrm{G}}=0,56176 \mathrm{rad}$. The Figure 7 shows the comparison between the interpolated signal and the ray tracing-modeled signal. Afterwards, the Figure 8 shows the same comparison with noisy data. Both curves hold an aperture of $3 \mathrm{~km}$ each.

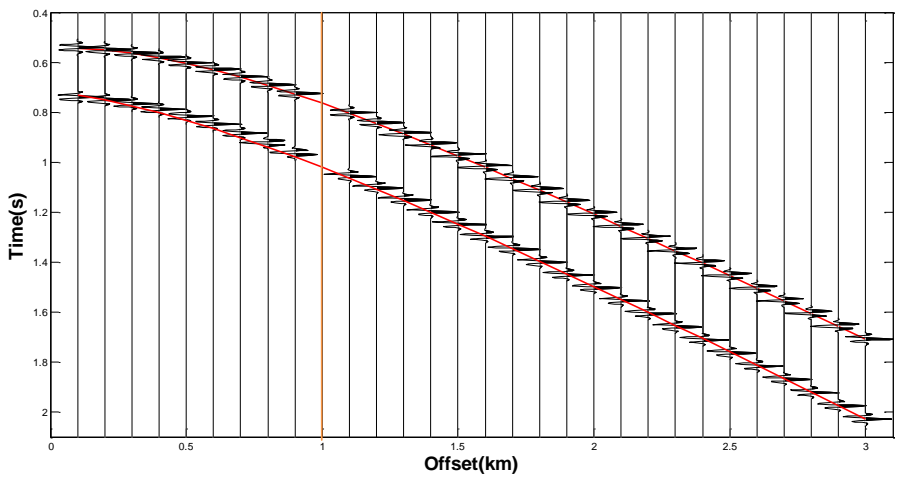

Figure 6 -CS-CRS curves fitting of the noise-free seismogram of model 1 . Orange line indicates the deleted trace. 

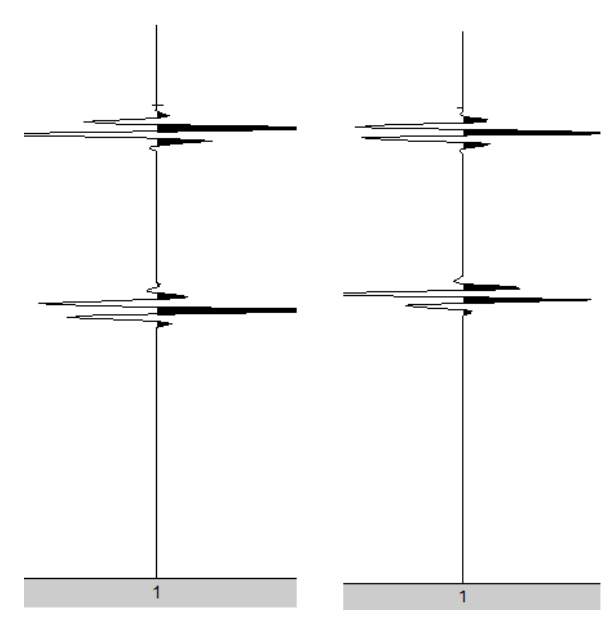

Figure 7 - Comparison between the noise-free interpolated and the ray tracing-modeled signal of the trace 10 in the seismogram of model 1. On the left is the interpolated trace and on the right is the ray tracing modeled trace.
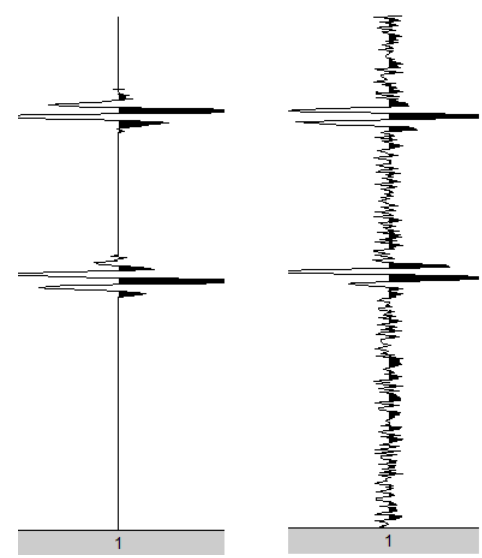

Figure 8 - Comparison between the noisy interpolated and the ray tracing-modeled signal of the trace 10 in the seismogram of model 1 . On the left is the interpolated trace and on the right is the ray tracing modeled trace.

In the figure 9 we have the four CS-CRS curves corresponding to the P-P and P-S reflection curves fitting the seismic section for the model 2. Moreover, the trace 10 in the offset $1 \mathrm{Km}$ is deleted. The fitting parameters for the red curve - which represents the P-P reflection of the first reflector- are $t_{0}=1,1370 \mathrm{~s}, \mathrm{~K}_{1}=0,4 \mathrm{~km}^{-1}, \beta_{\mathrm{G}}=0,7432$ rad and a CS-CRS curve aperture of $1.1 \mathrm{~km}$. For the green curve - which represents the P-P reflection of the second reflector - the fitting parameters are $t_{0}=1,7598 \mathrm{~s}$, $\mathrm{K}_{1}=0,3559 \mathrm{~km}^{-1}, \beta_{\mathrm{G}}=0,3862633 \mathrm{rad}$ and a CS-CRS curve aperture of $1.8 \mathrm{~km}$. For the blue curve - which represents the P-S reflection of the first reflector - the fitting parameters are $t_{0}=1,5062 \mathrm{~s}, \mathrm{~K}_{1}=0,2027 \mathrm{~km}^{-1}, \beta_{\mathrm{G}}=$ $0,42988 \mathrm{rad}$ and a CS-CRS curve aperture of $1.9 \mathrm{~km}$. And for yellow curve - which represents the P-S reflection of the second reflector - the fitting parameters are $t_{0}=$ $2,4083 \mathrm{~s}, \mathrm{~K}_{1}=0,143553 \mathrm{~km}^{-1}, \beta_{\mathrm{G}}=0,239961 \mathrm{rad}$ and $\mathrm{a}$ CS-CRS curve aperture of $2.5 \mathrm{~km}$. The Figure 10 shows the comparison between the interpolated signal and the ray tracing-modeled signal. Afterwards, the Figure 11 shows the same comparison with noisy data.

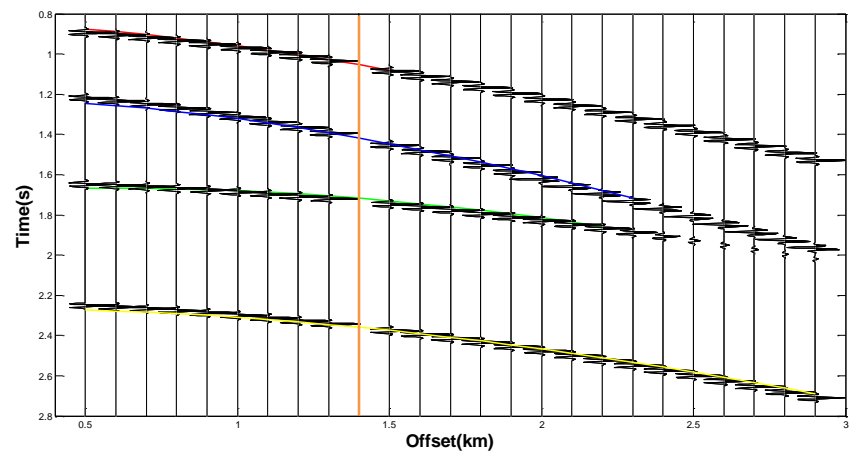

Figure 9 - CS-CRS curves fitting of the noise-free seismogram of model 2. Orange line indicates the deleted trace.
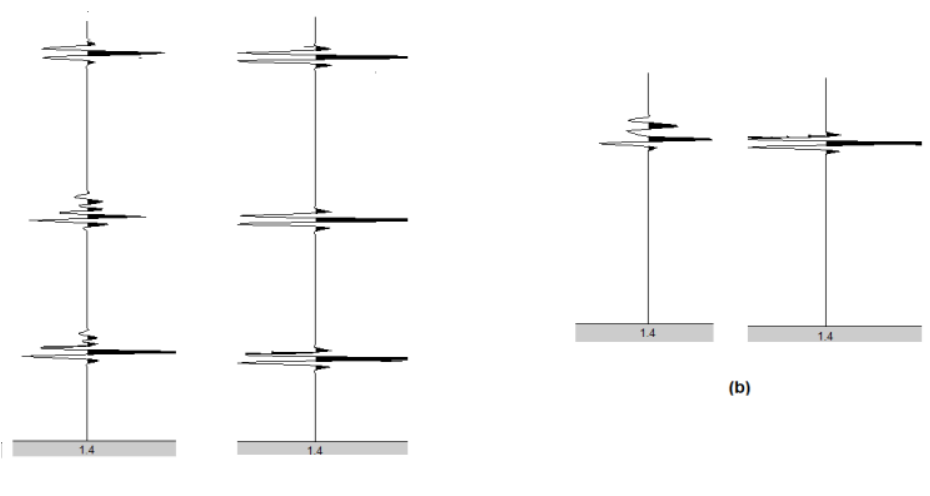

(b)

Figure 10 - Comparison between the noise-free interpolated and the ray tracing-modeled signal of the trace 10 in the seismogram of model 2. (a) The three first amplitudes. On the left is the interpolated trace and on the right is the ray tracing modeled trace. (b) The fourth amplitude. On the left is the interpolated trace and on the right is the ray tracing modeled trace.

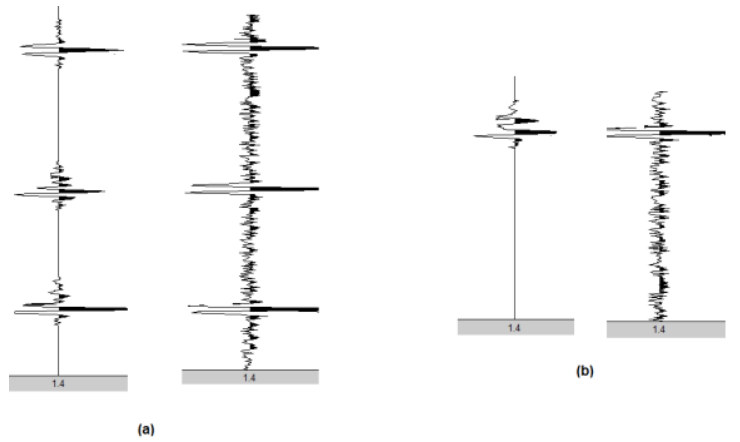

Figure 11 - Comparison between the noisy interpolated and the ray tracing-modeled signal of the trace 10 in the seismogram of the model 2. (a) The three first amplitudes. 
On the left is the interpolated trace and on the right is the ray tracing modeled trace. (b) The fourth amplitude. On the left is the interpolated trace and on the right is the ray tracing modeled trace.

In the figure 12 we have the four CS-CRS curves corresponding the $\mathrm{P}-\mathrm{P}$ and $\mathrm{P}-\mathrm{S}$ reflection curves fitting the seismic section for the model 3 . Moreover, the traces 10 in the offset $1 \mathrm{Km}$ and 20 in the offset $2 \mathrm{Km}$ are deleted. For the trace 10, the fitting parameters of the red curve - which represents the P-P reflection of the first reflector - are $t_{0}=0,9013 \mathrm{~s}, \mathrm{~K}_{1}=0,5547 \mathrm{~km}-1, \beta_{\mathrm{G}}=$ $0,98084 \mathrm{rad}$ and CS-CRS curve aperture of $1.6 \mathrm{~km}$. For the green curve - which represents the P-P reflection of the second reflector - the fitting parameters are $t_{0}=$ $1,0257 \mathrm{~s}, \mathrm{~K}_{1}=0,4552 \mathrm{~km}^{-1}, \beta_{\mathrm{G}}=0,715693 \mathrm{rad}$ and CSCRS curve aperture of $2.3 \mathrm{~km}$. For the blue curve - which represents the $\mathrm{P}-\mathrm{S}$ reflection of the first reflector - the fitting parameters are $t_{0}=1,1548 \mathrm{~s}, K_{1}=0,1299 \mathrm{~km}^{-1}, \beta_{\mathrm{G}}=$ $0,5610 \mathrm{rad}$ and CS-CRS curve aperture of $2.4 \mathrm{~km}$. And for yellow curve - which represents the $P$-S reflection of the second reflector - the fitting parameters are $t_{0}=1,1547 \mathrm{~s}$, $\mathrm{K}_{1}=0,1340 \mathrm{~km}^{-1}, \beta_{\mathrm{G}}=0,3737 \mathrm{rad}$ and CS-CRS curve aperture of $2.3 \mathrm{~km}$.

For the trace 20 we used the same parameters but different CS-CRS curves apertures. For the red curve we used an aperture of $2.2 \mathrm{~km}$. For the green curve we used an aperture of $3 \mathrm{~km}$. For the blue curve we used an aperture of $2.3 \mathrm{~km}$ ranging from the offset $0.7 \mathrm{~km}$ to $3 \mathrm{~km}$. And for the yellow curve we used an aperture of $2.1 \mathrm{~km}$

The comparison between the interpolated signal and the ray tracing-modeled signal for the trace 10 and 20 are shown in the figures 14 and 15, respectively. Similarly, the Figures 15 and 16 show the comparison between the noisy interpolated signal and nosiy ray tracing-modeled signal for the trace 10 and 20 , respectively.

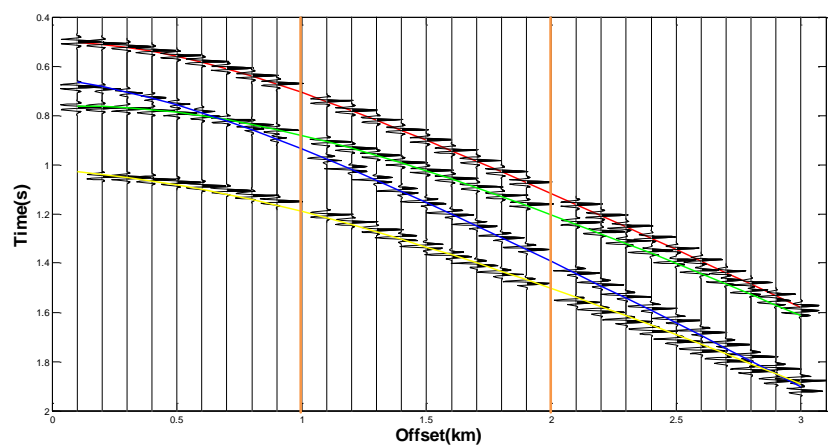

Figure 12 - CS-CRS curves fitting of the noise-free model 3. Orange lines indicate deleted traces.

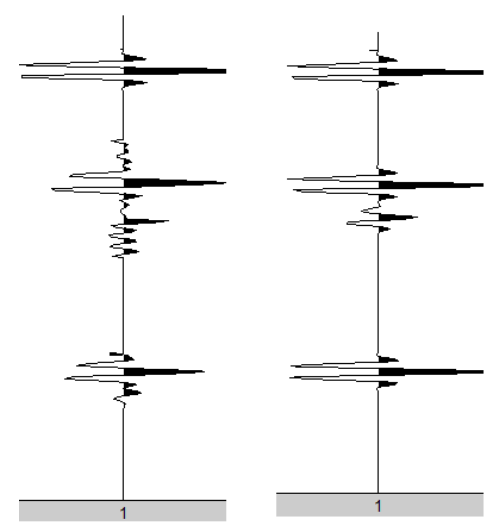

Figure 13 - Comparison between the noise-free interpolated and the ray tracing-modeled signal of the trace 10 in the model 3 . On the left is the interpolated trace and
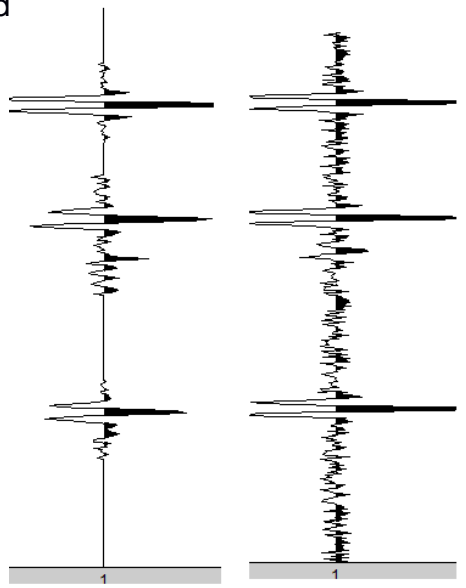

ed trace.

Figure 14 - Comparison between the noisy interpolated and the ray tracing-modeled signal of the trace 10 in the model 3. The left indicates the interpolated trace and the right indicates the modeled trace.
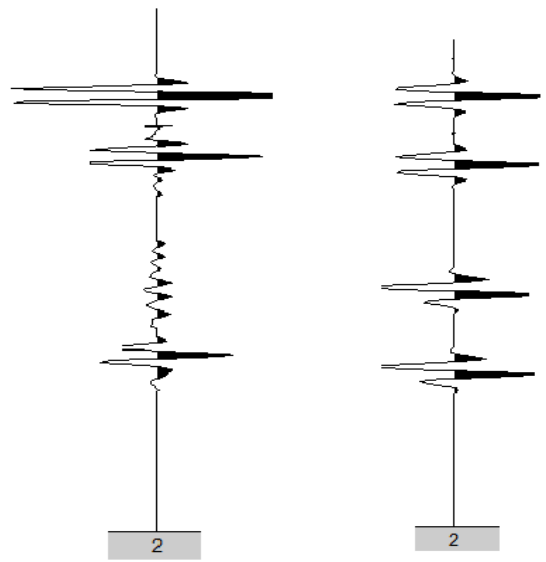

Figure 15 - Comparison between the noise-free interpolated and the ray tracing-modeled signal of the trace 20 in the model 3 . On the left is the interpolated trace and on the right is the ray tracing modeled trace. 

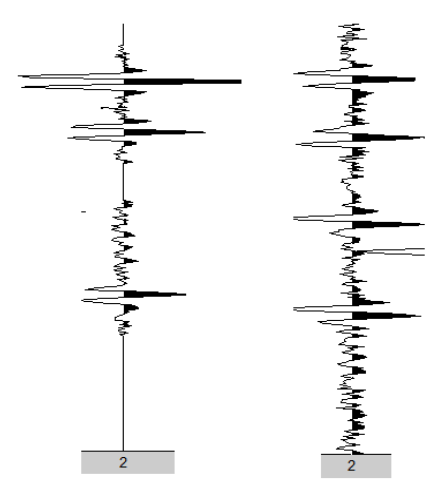

Figure 16 - Comparison between the noisy interpolated and the ray tracing-modeled signal of the trace 20 in the model 3. On the left is the interpolated trace and on the right is the modeled trace.

We verified that the interpolation of the deleted trace of the model 1 succeeded to approximate successfully the ray tracing-modeled trace in both noisy and noise-free sections. The interpolation of the model 2 also succeeded to approximate the modeled trace, however we realized the interference of others reflectors' information in the interpolated signal. On the other hand, the interpolated traces of the model 3 did not succeed to approximate the modeled trace.

For each model we chose an optimum aperture of the CS-CRS curve which could recover the better waveform of the signal, but even so the traces of model 3 did not produce a good result. Such ineffectiveness happens due to the process of stacking sums information which does not belong to the same reflection event generating a result with low signal-to-noise ratio, in this case each CSCRS curve summed amplitudes that belonged to different reflections.

It is important to point out that in the interpolation process it is necessary to choose an optimum aperture for the CSCRS operator which produces a good fitting and do not contaminate the final stacking with noise. The choice of this aperture is designated to the interpreter and there is not an automatic method for choosing it.

Therefore, the method of stacking using the CS-CRS approximation is effective in smooth/horizontal surfaces like layers influenced by low tectonics but fails in dip layers or environments with high tectonic activities such grabens and horsts.

\section{Conclusions}

We present in this work a new method of interpolation of P-P and P-S reflected waves seismic data through the FO-CRS approximation modified for the common shot case.

We applied the method in three different velocity models with noise and noise-free data. The method interpolated successfully the traces generated by smooth/horizontal reflectors but failed to interpolate the signal from dip layers, due to the destructive interferences of reflection events of P-P and P-S waves.

Further analysis should include inversion methods (data driven) to estimate the better CRS surface of Eq. 1 that fits the data, after separation of primary and converted waves seismograms, in order to avoid destructive interferences during the trace interpolation.

\section{Acknowledgements}

The authors thank to Coordenação de Aperfeiçoamento de Pessoal de Nível Superior and UFPA for the financial support.

\section{References}

Bortfeld, R. Geometrical ray theory: rays and traveltimes in seismic systems (second order approximation of the traveltimes). Geophysics, v. 1, p. 342-349, 1989.

Cerveny, V. 2001. Seismic Ray Theory. Cambridge Press. 713p.

Garabito, G.; Oliva, P.C.; Cruz, J.C.R. 2011. Numerical analysis of the finite offset commom reflection surface traveltime approximations. Journal of Applied Geophysics, v.74, p.89-99.

Hoecht, G.; Ricarte, P.; Bergler, S.; Landa, E. 2009. Operator-oriented CRS interpolation. Geophysical Prospecting, 57, p.957-979.

Jäger, R., Mann, J., Höcht, G., Hubral, P., 2001, Common Reflection Surface Stack: Images and attributes. Geophysics, V. 66, n. 1, p. 97-109.

Neidell, N. S.; Taner, M. T. 1971. Semblance and other coherency measures for multichannel data. Geophysics, v. 36, p. 482-497.

Spitz, S.. 1991. Seismic trace interpolation in the F-X domain. Geophysics, v. 56, p.785-796.

Sacchi, M.D.; Ulrych, T.J. 1996. Estimation of the discrete Fourier transform, a linear inversion approach.

Geophysics, 61, p. 1128-1136.

Trad, R.D.; Ulrych, T.J.; Sacchi, M.D. 2003. Latests views of the sparse Radon transform. Geophysics, v.68, p.386399

Trad, D. 2009. Five-dimensional interpolation: Recovering from acquisition constraints.Geophysics, v. 74, n. 6, p. 123-132.

Xu, S; Zhang, Y.; Pham, D.; Lambaré, G. , 2005b. Antileakage Fourier transform for seismic data regularization. Geophysics,v. 70, p. 87-95.

Wang, J.; Ng, M.; Perz, M. 2010. Seismic data interpolation by greedy local radon transform.Geophysics, v. $75, \quad n$. $6, \quad$ p. $225-234$.

Zhang, Y.; Bergler, S.; Hubral, P. 2001. Commonreflection-surface (CRS) stack for common offset. Geophysical Prospecting, 49, p.709-718. 